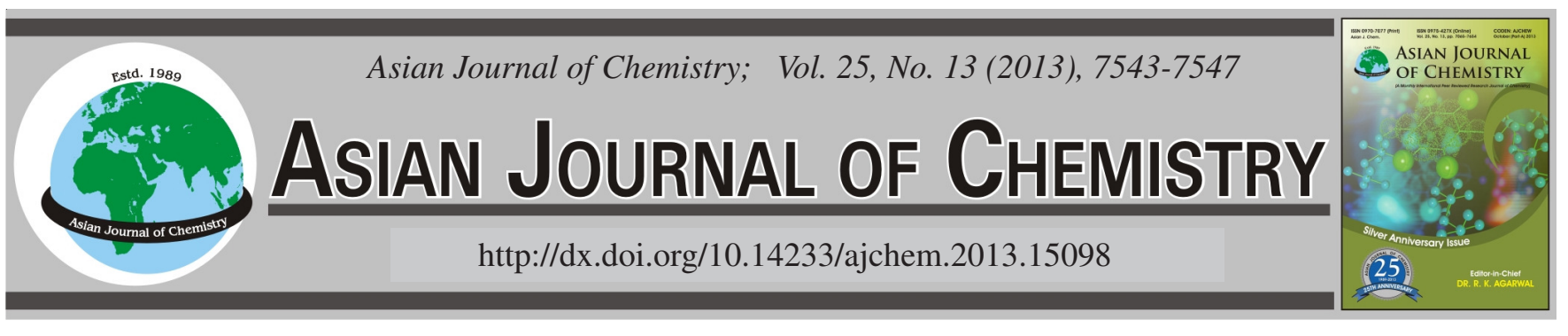

\title{
Vortex-Assisted Ionic Liquid Microextraction Coupled to Graphite Furnace Atomic Absorption Spectrometry for Preconcentration and Determination of Trace Levels of Cadmium in Real Samples
}

\author{
Mahmoud Chamsaz, Ali Sarafraz Yazdi and Fatemeh Dousti*
}

Department of Chemistry, Faculty of Sciences, Ferdowsi University of Mashhad, Mashhad, Iran

*Corresponding author: Fax: +98 5118796416; Tel: +98 511 8795162; E-mail: dousti.fatemeh@ gmail.com

\begin{abstract}
A simple and rapid vortex assisted ionic liquid based liquid-liquid microextraction technique was proposed for preconcentration of trace levels of cadmium. According to this method, the extraction solvent was dispersed into the aqueous sample by the assistance of vortex agitator. Cadmium preconcentration was mediated by chelation with ammonium pyrroldinedithiocarbamate and an ionic liquid, 1-hexyl3 -methylimidazolium hexafluorophosphate $\left([\mathrm{Hmim}]\left[\mathrm{PF}_{6}\right]\right)$, was chosen as the extraction solvent to extract the hydrophobic complex. Several variables such as sample $\mathrm{pH}$, concentration of ammonium pyrroldinedithiocarbamate, volume of $[\mathrm{Hmim}]\left[\mathrm{PF}_{6}\right]$ and extraction time were investigated in details and optimum conditions were obtained. Under the optimum conditions, the limit of detection (LOD) was $0.01 \mu \mathrm{g} \mathrm{L}^{-1}$ for $\mathrm{Cd}$ and relative standard deviation (RSD \%) for five replicate determinations of $0.05 \mu \mathrm{g} \mathrm{L} \mathrm{L}^{-1}$ was $5.2 \%$. The results for determination of cadmium in reference material, tap water and apple samples demonstrated the accuracy, recovery and applicability of the presented method.
\end{abstract}

Key Words: Microextraction, Ionic liquid, Preconcentration, APDC, Cadmium, Graphite furnace absorption spectrometry.

\section{INTRODUCTION}

In recent years, pollution of the environment by heavy metals has received considerable attention. These elements accumulate in living organisms and are of high toxic potential. Their wide technological use (fertilizers, mining, pigments), as well as their production from burning oil and coal and incineration of waste causes an extensive anthropogenic contamination of soil, air and water ${ }^{1}$. Cadmium is one of the heavy metals which is critical for the human health ${ }^{2}$. The most dangerous form of occupational exposure to cadmium is inhalation of fine dust and fumes or ingestion of highly soluble cadmium compounds. Inhalation of cadmium-containing fumes can result initially in metal fume fever but may progress to chemical pneumonitis, pulmonary edema and death ${ }^{3}$. Due to its low excretion rate (biological half-life of 10-30 years), it is accumulated in the body ${ }^{4}$. The FAO/WHO Joint Expert Committee on Food Additives recommended provisional maximum tolerable daily intake of cadmium from all sources (food, air and water) in the range of $1.0-1.2 \mu \mathrm{g} \mathrm{kg}^{-1}$ mass of body ${ }^{5}$. Therefore, determination of trace amounts of cadmium in environmental samples is of great importance. Different analytical techniques have been performed to determine cadmium in in various samples including flame atomic absorption spectrometry (FAAS $)^{6,7}$, graphite furnace atomic absorption spectrometry (GFAAS) ${ }^{8,9}$, inductively coupled plasma emission spectrometry (ICP-OES) ${ }^{10,11}$, inductively coupled plasma mass spectrometry (ICP-MS) ${ }^{12}$.

Graphite furnace atomic absorption spectrometry (GFAAS) has been widely used for determination of trace quantities of cadmium because of high sensitivity. Although the development of modern analytical instruments allows great enhancement in aspects of analysis, in many cases the available analytical instrumentation does not have enough sensitivity for the analysis of real samples. In order to achieve accurate, sensitive and reliable results at trace levels; preconcentration and separation steps are needed prior to analyte determination by GFAAS.

Several procedures such as liquid-liquid microextraction $\left(\right.$ LLME) ${ }^{13}$, solid phase extraction ${ }^{14}$ and cloud point extrac$\operatorname{tion}^{15,16}$ have been developed for separation and preconcentration of cadmium from different matrices. However, these methods often require large amounts of organic solvents of high purity and this may also result in environmental and safety problems due to volatilization of organic solvents.

Room temperature ionic liquids (RTILs) are a kind of burgeoning green solvents. Room temperature ionic liquid are organic salts that are liquid at room temperature ${ }^{17}$. Room 
temperature ionic liquids are composed by an organic cation and an organic or inorganic anion. Any salt that melts without decomposing or vaporizing usually yields an ionic liquid. Ionic liquids have many applications, such as powerful solvents and electrically conducting fluids (electrolytes). Salts that are liquid at near-ambient temperature are important for electric battery applications and have been used as sealants due to their very low vapor pressure. Additionally ionic liquids applies in analytical chemistry in different fields including: extractions, gas chromatography (GC), liquid chromatography (LC), capillary electrophoresis (CE), mass spectrometry (MS), electrochemistry, sensors and spectroscopy ${ }^{18,19}$. A novel modality of liquidphase microextraction (LPME) technique based on a ternary component solvent system as an alternative high-performance and powerful preconcentration method termed dispersive liquid-liquid microextraction (DLLME) has been introduced, which is simple, very fast and inexpensive ${ }^{20}$. But the amount of disperser solvent used is relatively high, so it is possible that the partition coefficient of the analytes into the extractant phase decreases. So, several methods have been introduced to eliminate the disperser solvents ${ }^{21-23}$.

In this work, vortex assisted ionic liquid based-liquid liquid microextraction (IL-based VALLME) method coupled to graphite furnace absorption spectrometry (GFAAS) was used for preconcentration and determination of trace levels of cadmium. Cadmium preconcentration was mediated by chelation with ammonium pyrroldinedithiocarbamate (APDC) reagent, followed by extraction with 1-hexyl-3-methylimidazolium hexafluorophosphate $\left([\mathrm{Hmim}]\left[\mathrm{PF}_{6}\right]\right)$ as room temperature ionic liquid. Under shaking of the solution with vortex agitator at $2500 \mathrm{rpm}$ (maximum setting), a vigorous vortex stream is formed in the whole of centrifuge tube which causes very fine droplets of ionic liquid to be produced. It is revealed that after formation of fine droplets, the surface area between extraction solvent and aqueous phase (sample) is large. Therefore, the cadmium-ammonium pyrroldinedithiocarbamate (APDC) complex is extracted into the extractant phase $\left([\mathrm{Hmim}]\left[\mathrm{PF}_{6}\right]\right)$ at a short time.

\section{EXPERIMENTAL}

The experiments were performed using a Zeeman Varian atomic absorption spectrometer (SpectrAA 220 Z-type), equipped with a graphitefurnace atomizer GTA-110. Zeeman background correction was employed to correct nonspecific absorbances. All measurements were performed using the peak height method. A cadmium hollow cathode lamp (Photron Co. Ltd., L233-series) and a pyrolytic coated graphite tube (Shimadzu part No. 206-69984-02) were used. The sample injection volume was $10 \mu \mathrm{L}$ in all the experiments. The instrumental parameters and temperature program for the graphite atomizer are listed in Table-1. Argon gas with $99.999 \%$ purity was purchased from Sabalan Gas Co. (Tehran, Iran) and was used as protecting and purge gas.

The $\mathrm{pH}$ values were measured with a $\mathrm{pH}$-meter (Metrohm 632, Switzerland) supplied with a glass-combined electrode. A vortex Gilson mixer (Villiers Le Bel, Germany) was used for thoroughly mixing of the solutions. Phase separation was assisted using Centurion Scientific Centrifuge (Model Andreas Hettich D72, Tuttlingen, Germany).
TABLE-1

APPLIED CONDITIONS FOR CADMIUM DETERMINATION WITH GFA SYSTEM Optimum analytical conditions

$\begin{array}{cc}\text { Lamp current } & 4 \mathrm{~mA} \\ \text { Wavelength } & 228.8 \\ \text { Spectral bandwidth } & 0.5 \mathrm{~nm} \\ \text { Signal processing } & \text { Peak height } \\ \text { Purge gas } & \mathrm{Ar} \\ \text { ck ground correction } & \mathrm{D} 2\end{array}$

Back ground correction
Furnace program for GFAAS

\begin{tabular}{cccc}
\multicolumn{4}{c}{ Furnace program for GFAAS } \\
\hline Steps & $\begin{array}{c}\text { Temperature } \\
\left({ }^{\circ} \mathrm{C}\right)\end{array}$ & Time $(\mathrm{s})$ & $\begin{array}{c}\text { Argon flow } \\
\text { rate }(\mathrm{L} / \mathrm{min})\end{array}$ \\
\hline 1 & 85 & 5 & 3 \\
2 & 95 & 40 & 3 \\
3 & 120 & 10 & 3 \\
4 & 600 & 30 & 3 \\
5 & 1800 & 3 & 0 \\
6 & 2500 & 2 & 3 \\
\hline
\end{tabular}

All reagents were of analytical reagent grade and deionized water was used throughout. A stock solution of $1000 \mathrm{mg} \mathrm{L}^{-1}$ cadmium(II) ion was prepared by dissolving the appropriate amounts of cadmium chloride (Merck, Darmstadt, Germany) in $1 \% \mathrm{HNO}_{3}$. Working standard solutions were prepared freshly at various concentrations by diluting the stock standard solution with deionized water. $\mathrm{HNO}_{3}(65 \%), \mathrm{H}_{2} \mathrm{SO}_{4}(98 \%)$ and $\mathrm{H}_{2} \mathrm{O}_{2}(30 \%)$ were used for sample digestion. The chelating agent, ammonium pyrroldinedithiocarbamate (APDC), was purchased from fluka. Ammonium pyrroldinedithiocarbamate (APDC, $4 \% \mathrm{w} / \mathrm{v}$, Fluka) was prepared daily by dissolving $1 \mathrm{~g}$ of APDC in $25 \mathrm{~mL}$ ultra-pure water. 1-Hexyl-3-methylimidazolium hexafluorophosphate $\left([\mathrm{Hmim}]\left[\mathrm{PF}_{6}\right]\right)$ was employed as the extractant solvent and purchased from Fluka. The $\mathrm{pH}$ adjustment was made with $0.1 \mathrm{~mol} \mathrm{~L}^{-1}$ hydrochloric acid (for acidic $\mathrm{pH}$ values) or sodium hydroxide solution (for basic $\mathrm{pH}$ values).

All $10 \mathrm{~mL}$ conical-bottom glass centrifuge tube (extraction vessel) were rinsed off with $0.1 \mathrm{~mol} \mathrm{~L}^{-1} \mathrm{HNO}_{3}$ for cleaning of any inorganic compounds and washed with doubly deionized water followed by acetone for proper sedimentation of fine droplets of the extraction solvent in the centrifuging step. A solution of $500 \mathrm{mg} \mathrm{L}^{-1}$ ammonium dihydrogen phosphate $\left(\mathrm{NH}_{4} \mathrm{H}_{2} \mathrm{PO}_{4}\right)$ (Merck, Darmstadt, Germany), was used as chemical modifier.

\section{Preparation of real samples}

Water sample: Water sample including tap water was collected from local sources. Seven milliliter of sample solution was used for the analysis after addition of ammonium pyrroldinedithiocarbamate (APDC) and adjusting their $\mathrm{pH}$ to 4, with $\mathrm{HCl}$ solution.

Apple: $2.5 \mathrm{~g}$ of dried red apple sample (Neyshabur, Iran) and $20 \mathrm{~mL}$ of concentrated $\mathrm{HNO}_{3}$ was heated on a hot plate at a fairly low temperature in the glass beaker to dryness. Then, $25 \mathrm{~mL}$ of concentrated $\mathrm{HCl}$ was added and heating was repeated to near dryness. Under the heating conditions, concentrated hydrogen peroxide was added and heated to complete the digestion. After cooling of solution to room temperature and dilution to $50 \mathrm{~mL}$ with deionized water, $7 \mathrm{~mL}$ of this solution was analyzed according to the analytical procedure. 
Reference material: In order to evaluate the accuracy of the proposed method, a standard rock reference material, JSD3, obtained from the geological survey of Japan was analyzed for its cadmium content. The rock sample $(0.5 \mathrm{~g})$ was dissolved in $10 \mathrm{~mL}$ a mixture of $\mathrm{HF}(500 \mathrm{~mL}), \mathrm{HNO}_{3}(45 \mathrm{~mL})$ and $\mathrm{H}_{2} \mathrm{SO}_{4}$ $(165 \mathrm{~mL})$ in a Teflon beaker and heated until $2 \mathrm{~mL}$ of solution was remained. To this solution concentrated $\mathrm{HNO}_{3}(8 \mathrm{~mL})$ was added. After heating, it was treated with distilled water to give a clear solution and was finally made to $100 \mathrm{~mL}$ by further addition of distilled water. $10 \mathrm{~mL}$ of this solution diluted to $100 \mathrm{~mL}$ and analyzed for its $\mathrm{Cd}^{2+}$ content according to the proposed procedure.

Microextraction procedure: Twenty-five milliliter of aqueous sample solution containing $0.4 \mu \mathrm{g} \mathrm{L}^{-1} \mathrm{Cd}^{2+}$ and $0.4 \%$ (w/v) of APDC at $\mathrm{pH} \mathrm{4,} \mathrm{was} \mathrm{prepared.} 7 \mathrm{~mL}$ of this solution was transferred into a conical-bottom glass centrifuge tube and $60 \mu \mathrm{L}$ of $[\mathrm{Hmim}]\left[\mathrm{PF}_{6}\right]$ ionic liquid was added to the mixture. The resulting solution was vigorously shaken with vortex agitator for $6 \mathrm{~min}$ at $2500 \mathrm{rpm}$. Under the shaking solution very fine droplets of ionic liquid is formed through the solution and the cadmium-APDC complex, was extracted into the fine droplets of $[\mathrm{Hmim}]\left[\mathrm{PF}_{6}\right]$ at a relatively short time. In order to accelerate phase separation, the solution was centrifuged for $5 \mathrm{~min}$ at $4000 \mathrm{rpm}$. After this step, the ionic liquid-phase was settled at the bottom of the tube and the aqueous phase was discarded with a syringe. $10 \mu \mathrm{L}$ of ionic liquid phase and $10 \mu \mathrm{L}$ of $500 \mathrm{mg} \mathrm{L}^{-1} \mathrm{NH}_{4} \mathrm{H}_{2} \mathrm{PO}_{4}$, as chemical modifier, was subsequently injected into the graphite tube for determination of cadmium.

\section{RESULTS AND DISCUSSION}

There are different factors that affect the extraction process such as $\mathrm{pH}$, concentration of chelating agent, amounts of ionic liquid, extraction time and interfering ions. It is very important to optimize these parameters in order to obtain high recovery and enrichment factor.

Effect of pH: Sample $\mathrm{pH}$ has a significant effect on the formation of Cd-APDC complex and its subsequent extraction into ionic liquid phase. In order to evaluate the effect of $\mathrm{pH}$ on the extraction efficiency of $\mathrm{Cd}^{2+}$, the $\mathrm{pH}$ values of sample solutions was studied in the range of 2-10 and the results are shown in Fig. 1. As it is demonstrated, the absorbance of cadmium ion is at it's maximum in the $\mathrm{pH}$ value of 4 . At higher $\mathrm{pH}$ values cadmium can react with hydroxide ion and the absorbance decreases. So, $\mathrm{pH} 4$ was chosen as the optimum value.

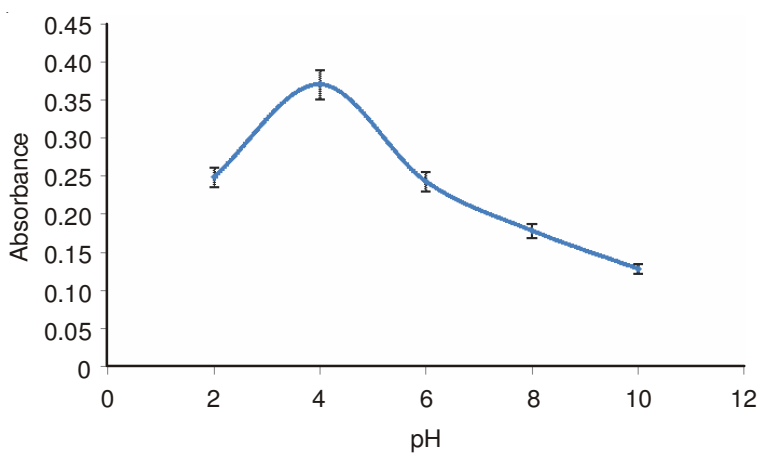

Fig. 1. Effect of $\mathrm{pH}$ on recovery of cadmium. Conditions: $0.4 \mu \mathrm{gL}^{-1} \mathrm{Cd}^{2+}$, $0.4 \%(\mathrm{w} / \mathrm{v})$ of APDC, $60 \mu \mathrm{L}$ of $[\mathrm{Hmim}]\left[\mathrm{PF}_{6}\right]$, extraction time $5 \mathrm{~min}$
Effect of APDC concentration: Concentration of complexing reagent is a critical variable to be optimized in preconcentration methods. Thus, it is highly important to establish the minimal reagent concentration that leads to total complex formation while achieving the highest extraction. In this work, ammonium pyrroldinedithiocarbamate(APDC) was used as the chelating agent due to the highly hydrophobic nature of its metal chelates. The effect of concentrations of APDC was investigated in the range of $0.2-1.0 \%(\mathrm{w} / \mathrm{v})$. The results are given in Fig. 2 and demonstrate that the absorbance of cadmium increases with an increasing the ligand concentration up to $0.4 \%(\mathrm{w} / \mathrm{v})$ and then decreased with further increasing of the ligand concentration. It seems that reduction of extraction at high concentration of APDC is due to the extraction of APDC itself, which can easily saturate the small volume of extraction solvent. Thus, a concentration of $0.4 \%$ (w/v) was selected as the optimum value.

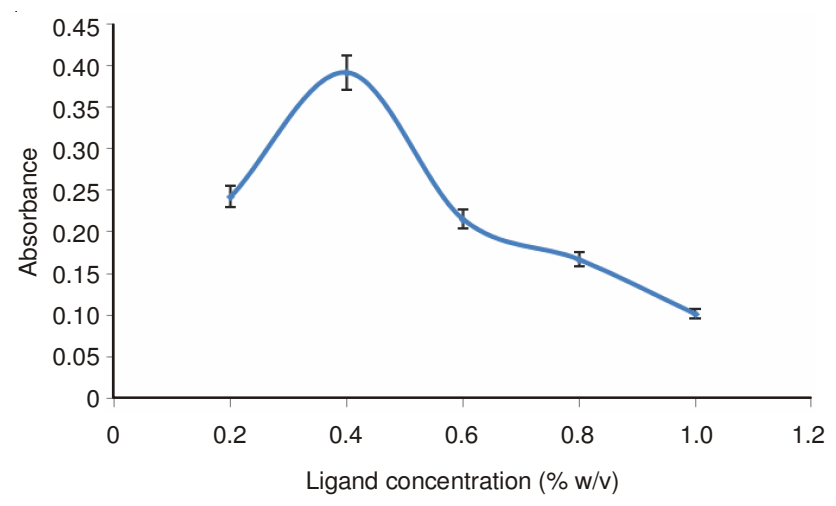

Fig. 2. Effect of APDC concentration on the recovery factor. Conditions: $\mathrm{pH}: 4,0.4 \mu \mathrm{g} \mathrm{L}{ }^{-1} \mathrm{Cd}^{2+}, 60 \mu \mathrm{L}$ of $\left[\mathrm{Hmim}^{2+}\left[\mathrm{PF}_{6}\right]\right.$, extraction time 5 $\min$

Effect of [Hmim][PF$]$ volume: The amount of $[\mathrm{Hmim}]\left[\mathrm{PF}_{6}\right]$ ionic liquid used in this preconcentration procedure is a critical factor for obtaining high recovery of the analyte. The volume of ionic liquid was studied in the range of 20-100 $\mu \mathrm{L}$. As can be seen in Fig. 3, by increasing the volume of [Hmim] $\left[\mathrm{PF}_{6}\right]$, the absorbance increased up to $60 \mu \mathrm{L}$ and then decreased by further increasing of the acceptor phase volume. Thus, $60 \mu \mathrm{L}$ of $[\mathrm{Hmim}]\left[\mathrm{PF}_{6}\right]$ was employed as the optimum value.

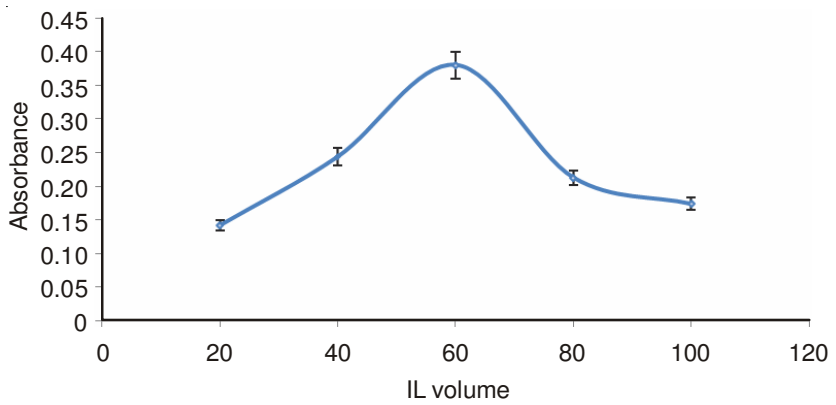

Fig. 3. Effect of amounts of room temperature ionic liquid on the recovery factor. Conditions: $\mathrm{pH}: 4,0.4 \mu \mathrm{g} \mathrm{L}^{-1} \mathrm{Cd}^{2+}, 0.4 \%$ (w/v) of APDC, extraction time $5 \mathrm{~min}$

Effect of the extraction time: Optimal extraction time is necessary in order to achieve equilibrium. The influence of 
the extraction time was evaluated in the range of 3-10 min at constant experimental conditions. The results (Fig. 4) show that the absorbance increased by increasing the extraction time up to $6 \mathrm{~min}$ and then remained constant up to $10 \mathrm{~min}$. Therefore, in order to achieve a high enrichment factor; an extraction time of 6 min was chosen as the optimum value.

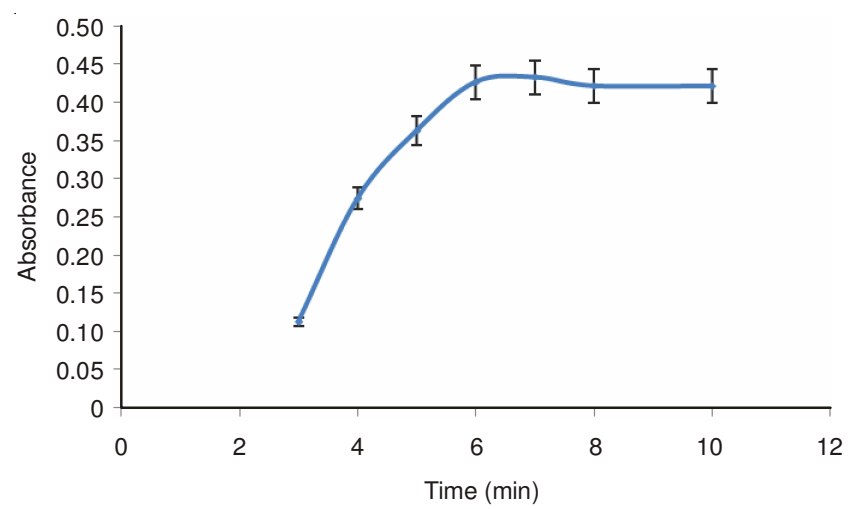

Fig. 4. Effect of extraction time on the recovery factor. Conditions: $\mathrm{pH}$ : 4 , $0.4 \mu \mathrm{g} \mathrm{L}^{-1} \mathrm{Cd}^{2+}, 0.4 \%$ (w/v) of APDC, $60 \mu \mathrm{L}$ of $[\mathrm{Hmim}]\left[\mathrm{PF}_{6}\right]$

Effect of centrifuge conditions: The effect of centrifugation rate on the absorbance was studied in the range of 1000$6000 \mathrm{rpm}$. It was found that over $4000 \mathrm{rpm}$, ionic liquid phase was completely settled, so that the rate of $4000 \mathrm{rpm}$ was selected as optimum point. At the optimum rate, absorbance was studied as a function of centrifugation time. Five minutes was selected as optimum centrifugation time, because complete separation occurred at this time.

Effect of ionic strength: In general, the addition of a salt plays an important role in conventional extraction process. Various experiments were performed by adding different amounts of $\mathrm{KCl}\left(0-1 \mathrm{~mol} \mathrm{~L}^{-1}\right)$, while other parameters were kept constant. The obtained results showed that the salt addition had no significant effect on the extraction of the proposed method. Therefore, all the extraction experiments were performed without the addition of salt.

Effect of coexisting ions: In order to demonstrate the selectivity of the developed microextraction system for determination of cadmium, the effect of different concomitant ions was evaluated. The interferences were studied by analyzing $7 \mathrm{~mL}$ solution containing $0.4 \mu \mathrm{g} \mathrm{L}^{-1} \mathrm{Cd}^{2+}$. An ion was considered to interfere when its presence produced a variation of more than $5 \%$ in the absorbance of the sample. The results are shown in Table-2. As it is shown, some of the species tested, such as $\mathrm{Cu}^{2+}, \mathrm{Zn}^{2+}, \mathrm{Fe}^{3+}$ and $\mathrm{Ni}^{2+}$ did interfere. The interfering effects of these ions can be eliminated by using $0.02 \mathrm{~mol} \mathrm{~L}^{-1}$ of $\mathrm{SCN}^{-}$for $\mathrm{Fe}^{3+}$ ions, a mixture of $0.01 \mathrm{~mol} \mathrm{~L}^{-1}$ of ascorbic acid and $0.01 \mathrm{~mol} \mathrm{~L}^{-1}$ of $\mathrm{KI}$ for $\mathrm{Ni}^{2+}$ ions and the $\mathrm{Zn}^{2+}$ and $\mathrm{Cu}^{2+}$ interferences were eliminated in the presence of $0.01 \mathrm{~mol} \mathrm{~L}^{-1}$ ascorbic acid and $0.01 \mathrm{~mol} \mathrm{~L}^{-1} 1,10$-phenanthroline.

Analytical figures of merit: Above $90 \%$ extraction was achieved for cadmium when the procedure was performed under the optimal experimental conditions. The calibration graph was linear between 0.04 and $0.8 \mu \mathrm{g} \mathrm{\textrm {L } ^ { - 1 }}$ with a correlation coefficient of 0.9975 . The regression equation after the preconcentration procedure was $\mathrm{A}=1.556 \mathrm{C}+0.0079$, where

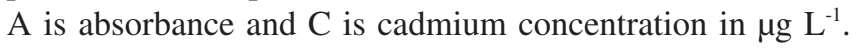

\begin{tabular}{ccc}
\multicolumn{3}{c}{ TABLE-2 } \\
EFFECT OF DIVERSE IONS ON THE \\
\multicolumn{3}{c}{ DETERMINATION OF 0.4 $\mu \mathrm{L} \mathrm{L}^{-1} \mathrm{Cd}^{2+}$ OF CADMIUM } \\
\hline Coexisting ions & Molar ratio (ion/cadmium) & Recovery (\%) \\
\hline $\mathrm{Cl}^{-}$ & 3000 & 98.0 \\
$\mathrm{CO}_{3}^{2-}, \mathrm{C}_{2} \mathrm{O}_{4}^{2-}$ & 2000 & 96.5 \\
$\mathrm{PO}_{4}^{3-}, \mathrm{NO}_{3}^{-}$ & 1800 & 98.4 \\
$\mathrm{SO}_{4}^{2-}, \mathrm{CH}_{3} \mathrm{COO}^{-}$ & 1000 & 97.3 \\
$\mathrm{Na}^{+}$ & 4000 & 102.8 \\
$\mathrm{~K}^{+}$ & 3000 & 97.5 \\
$\mathrm{Co}^{2+}$ & 2000 & 97.0 \\
$\mathrm{Cr}^{3+}$ & 1800 & 96.3 \\
$\mathrm{Mn}^{2+}$ & 1800 & 96.3 \\
$\mathrm{Mg}^{2+}$ & 1500 & 96.5 \\
$\mathrm{Ca}^{2+}$ & 1500 & 97.2 \\
$\mathrm{Ba}^{2+}$ & 1000 & 96.7 \\
$\mathrm{~Pb}^{2+}$ & 50 & 98.3 \\
$\mathrm{Fe}^{2+}$ & 20 & 96.1 \\
$\mathrm{Zn}^{2+}$ & 10 & 97.0 \\
$\mathrm{Cu}^{2+}$ & 10 & 96.7 \\
$\mathrm{Ni}^{2+}$ & 10 & 96.0 \\
\hline
\end{tabular}

The equation of the calibration curve before the preconcentration procedure was $\mathrm{A}=0.0509 \mathrm{C}+0.0119$ within a dynamic range from $0.4-10 \mu \mathrm{g} \mathrm{L}^{-1}$. The detection limit based on three times of the standard deviation of the blank signals $(n=8)$ was $0.01 \mu \mathrm{g} \mathrm{L}^{-1}$. The relative standard deviation (RSD) resulting from the analysis of five replicate solution containing $0.05 \mu \mathrm{g}$ $\mathrm{L}^{-1} \mathrm{Cd}^{2+}$ was $5.2 \%$. Enrichment factor, calculated as the ratio of the volume of the aqueous phase $(7 \mathrm{~mL})$ and the final volume of the ionic liquid-phase $(60 \mu \mathrm{L})$, was 116.7 times. The enhancement factor defined as the slope ratio of two calibration curves for $\mathrm{Cd}^{2+}$ with and without preconcentration step was 30 . The sensitivity of proposed method for determination of cadmium based on $0.0044 / \mathrm{m}$ (where $\mathrm{m}$ is the slope of calibration curve)

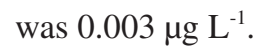

TABLE-3

RESULTS (MEAN \pm STANDARD DEVIATION BASED ON THREE REPLICATE ANALYSIS) OF DETERMINATION OF CADMIUM IN REAL SAMPLE

\begin{tabular}{cccc}
\multicolumn{4}{c}{ OF CADMIUM IN REAL SAMPLE } \\
\hline Sample & Spiked $\left(\mu \mathrm{g} \mathrm{L}^{-1}\right)$ & Found $\left(\mu \mathrm{g} \mathrm{L}^{-1}\right)$ & Recovery $(\%)$ \\
\hline \multirow{2}{*}{ Tap water $^{\mathrm{b}}$} & 0 & $\mathrm{ND}^{\mathrm{a}}$ & - \\
& 0.2 & $0.22 \pm 0.02$ & 110.0 \\
& 0.5 & $0.51 \pm 0.01$ & 102.0 \\
\hline \multirow{2}{*}{ Apple sample } & 0 & $\mathrm{ND}$ & - \\
& 0.5 & $0.52 \pm 0.02$ & 104.0 \\
\hline${ }^{\mathrm{a}}$ Not detected; b
\end{tabular}

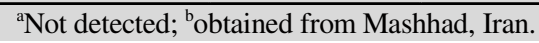

TABLE-4

DETERMINATION OF CADMIUM IN A CERTIFIED

REFERENCE MATERIAL. RESULTS (MEAN \pm STANDARD DEVIATION BASED ON THREE REPLICATE ANALYSIS)

\begin{tabular}{lccc} 
Sample & Certificated $\left(\mu \mathrm{g} \mathrm{g}^{-1}\right)$ & Found $\left(\mu \mathrm{g} \mathrm{g}^{-1}\right)$ & Recovery $(\%)$ \\
\hline
\end{tabular}

$\begin{array}{llll}\text { JSD3 } & 1.045 \pm 0.02 & 1.14 & 109.1\end{array}$

Analysis of real samples: In order to evaluate the capability of the proposed method, the developed procedure was applied to determine of cadmium in several samples including tap water and apple samples. In order to demonstrate the validity of this method, recovery experiments were also carried out by spiking the samples with different amounts of standard cadmium solution before any pretreatment. Table- 3 shows the 


\begin{tabular}{|c|c|c|c|c|c|c|c|}
\hline \multicolumn{8}{|c|}{$\begin{array}{c}\text { TABLE-5 } \\
\text { COMPARISON OF VALLME WITH OTHER METHODS FOR DETERMIN }\end{array}$} \\
\hline Method & $\begin{array}{l}\mathrm{LOD}^{\mathrm{a}} \\
\left(\mathrm{ngL}^{-1}\right)\end{array}$ & $\begin{array}{c}\mathrm{RSD}^{\mathrm{b}} \\
(\%)\end{array}$ & $\begin{array}{l}\text { Enrichment } \\
\text { factor }\end{array}$ & $\begin{array}{c}\text { Sample } \\
\text { consumption }(\mathrm{mL})\end{array}$ & $\begin{array}{l}\text { Time } \\
(\min )\end{array}$ & $\begin{array}{l}\text { Calibration } \\
\text { range }\left(\text { ng L }^{-1}\right)\end{array}$ & References \\
\hline On-line solvent extraction-GF AAS & 2.8 & 3.2 & 24.6 & 14.0 & 2 & $6-300$ & 24 \\
\hline Co-precipitation-GF AAS & 2.9 & 3.2 & 100 & 100.0 & $>30$ & $100-4000$ & 25 \\
\hline On-line SPE-GF AAS & 1.3 & 1.3 & 59.4 & 3.0 & 4 & $20-200$ & 26 \\
\hline CPE-GF AAS & 5.9 & 2.1 & 50 & 10.0 & $>30$ & $0-20.0$ & 27 \\
\hline SDME-GF AAS & 0.7 & 7.4 & 65 & 5.0 & $>10$ & $10-1000$ & 28 \\
\hline DLLME-GF AAS & 0.6 & 3.5 & 125 & 5.0 & $>30$ & $0-20.0$ & 29 \\
\hline VALLME-GF AAS & 10 & 5.2 & 116.7 & 7.0 & 6 & $40-800$ & This work \\
\hline
\end{tabular}

obtained results. The values of recoveries confirm the validity of the proposed method. Additionally, the accuracy of the proposed method was evaluated by analyzing a standard rock reference material jsd-3, obtained from the geological survey of japan, with the certified $\mathrm{Cd}^{2+}$ content of $1.045 \pm 0.02 \mu \mathrm{g} \mathrm{g}^{-1}$. It was found that the analytical results were in good agreement with the certified values as shown in Table- 4 .

Comparison of the proposed procedure with other methods: A comparison of the proposed method with others reported for preconcentration of cadmium is shown in Table5. The VALLME method has numerous advantages including rapidness, simplicity, low cost, low toxicity and relatively high enrichment factor. Although the results obtained in this research were primarily focused on $\mathrm{Cd}$ determination, the system may be readily applied for the determination of other metals with the help of various chelating agents and organic solvents.

\section{Conclusion}

The proposed vortex assisted ionic liquid based-liquidliquid microextraction (VALLME) procedure using [ $\mathrm{Hmim}]\left[\mathrm{PF}_{6}\right]$ as extractant solvent combined with GFAAS was successfully used for preconcentration and determination of cadmium at trace levels. The proposed method employs a vortex shaker system for the formation of vortex stream that accelerates the cadmium complex extraction to the extractant ionic liquid. This procedure is simple, fast and sensitivite for cadmium determination in environmental samples.

\section{ACKNOWLEDGEMENTS}

The authors wish to thank the Ferdowsi University of Mashhad mashhad for the financial support of this Project (No. p/347 September 2009).

\section{REFERENCES}

1. M.P. Waalkes, S. Rehm and M.G. Cherian, Toxicol. Sci., 54, 110 (2000).

2. H. Seiler and H. Sigel, Handbook on Metals in Clinical and Analytical Chemistry, New York: Marcel Dekker (1994).
3. U.S. Department of Health and Human Services, Public Health Service, Agency for Toxic Substances and Disease Registry (ATSDR), Toxicological Profile for Cadmium (2012).

4. H.G. Seiler, A. Sigel and H. Sigel, Handbook on Toxicity of Inorganic Compounds, New York: Marcel Dekker (1998).

5. FAO/WHO Joint Expert Committee on Food Additives, WHO Tech. Rep. Senal No. 50532 (1972).

6. E.V. Orala, I. Dolak, H. Temel and B. Ziyadanogullari, J. Hazard. Mater., 186, 724 (2011).

7. S. Mahpishanian and F. Shemirani, Talanta, 82, 471 (2010).

8. E.I.V. Alonso, L.P. Gil, M.T.S. Cordero, A.G. de Torres and J.M.C. Pavón, J. Anal. At. Spectrom., 16, 293 (2001).

9. S. Antakli, N. Sarkis and A.A. Hajar, Asian J. Chem., 25, 1068 (2013).

10. S. Cerutti, M.F. Silva, J.A. Gasquez, R.A. Olsinaa and L.D. Martinez, Spectrochim. Acta B, 58, 43 (2003).

11. D. Atanassova, V. Stefanova and E. Russeva, Talanta, 47, 1237 (1998).

12. M. Montes-Bayon, D. Profrock, A. Sanz-Medel and A. Prange, J. Chromatogr. A, 1114, 138 (2006).

13. E.M. Martinis, R.A. Olsina, J.C. Altamirano and R.G. Wuilloud, Anal. Chim. Acta, 628, 4 (2008).

14. N. Pourreza and K. Ghanemi, J. Hazard. Mater., 178, 566 (2010).

15. P.R. Aranda, R.A. Gil, S. Moyano, I.D. Vito and L.D. Martinez, Talanta, 77, 663 (2008).

16. J.L. Manzoori, H. Abdolmohammad-Zadeh and M. Amjadi, Talanta, 71, 582 (2007).

17. J.L. Anderson, D.W. Armstrong and G.T. Wei, Anal. Chem., 78, 2892 (2006).

18. K. Tian, Y. Wang, Y. Chen, X. Chen and Z. Hu, Talanta, 72, 587 (2007).

19. P.L. Laamanen, S. Busi, M. Lahtinen and R. Matilainen, J. Chromatogr. A, 1095, 164 (2005).

20. S. Berijani, Y. Assadi, M. Anbia, M.R.M. Hosseini and E. Aghaee, J. Chromatogr. A, 1123, 1 (2006).

21. Q.X. Zhou, H.H. Bai, G.H. Xie and J.P. Xiao, J. Chromatogr. A, 1177, 43 (2008).

22. H. Yan, B. Liu, J. Du, G. Yang and K.H. Row, J. Chromatogr. A, 1217, 5152 (2010).

23. M. Chamsaz, A. Atarodi, M. Eftekhari, S. Asadpour and M. Adibi, J. Adv. Res., 4, 35 (2012).

24. A.N. Anthemidis, G.A. Zachariadis and J.A. Stratis, J. Anal. At. Spectrom., 18, 238 (2003).

25. K. Atsumi, T. Minami and J. Uada, Anal. Sci., 21, 647 (2005).

26. J. Wang and E.H. Hansen, J. Anal. At. Spectrom., 17, 248 (2002).

27. X.S. Zhu, X.H. Zhu and B.S. Wang, Microchim. Acta, 154, 95 (2006).

28. Z. Fan and W. Zhou, Spectrochim. Acta B, 61, 870 (2006).

29. E.Z. Jahromi, A. Bidari, Y. Assadi, M.R.M. Hosseini and M.R. Jamali, Anal. Chim. Acta, 585, 305 (2007). 